\title{
How do children with a chronic or long-term illness perceive their school re-entry after a period of homebound instruction?
}

\author{
Hannah Boonen $^{\mathrm{a}} \&$ Katja Petry ${ }^{\mathrm{a}}$ \\ ${ }^{\mathrm{a}} \mathrm{KU}$ Leuven; Parenting and Special Education Research Unit
}

\begin{abstract}
Background. A considerable number of children are confronted with a chronic or long-term illness in their lives. For these children absenteeism is problematic, because education plays a major role in stimulating their cognitive development and in promoting a sense of normalcy and psychosocial wellbeing. In the literature, a great deal of attention has been paid to school reintegration programmes, which try to counter the barriers that these children may face when they return to school. Another way of surmounting these barriers is through the use of homebound instruction, in which the educational process for the child is continued during the period of absence. Despite the growing awareness of the necessity of education for these children, there is still little empirical research available addressing programmes that facilitate school re-entry.
\end{abstract}

Methods. The major goal of this study is to investigate how parents and their children with a chronic or long-term illness perceive school re-entry after a period of homebound instruction, by using a descriptive-explorative, multi-informant research design. Participants were 60 children and their parents who filled in a self-constructed questionnaire.

Results. Both parents and children perceived the period of homebound instruction, as well as their school re-entry, predominantly positively. Most of the children stated that they had been able to keep up with their subjects, and that they had good contact with their peers when they returned to school. According to parents, homebound instruction made a positive contribution to the school reentry of their child.

Conclusions. The current study is one of the first to explore the school re-entry of children with a chronic or long-term illness. According to both parents and children, the school re-entry process passed off positively. However, more research is needed with regard to the quality of education and the programmes aimed at facilitating school re-entry.

Keywords: chronic illness, homebound instruction, school re-entry

This is the peer reviewed version of the following article: Boonen, H., Petry, K. (2012). How do children with a chronic or long-term illness perceive their school re-entry after a period of homebound instruction?. Child:

Care, Health and Development, 38 (4), 490-496, which has been published in final form at http://onlinelibrary.wiley.com/doi/10.1111/i.1365-2214.2011.01279.x/full. This article may be used for noncommercial purposes in accordance with Wiley Terms and Conditions for self-archiving. 


\section{INTRODUCTION}

A considerable number of children are confronted with chronic or long-term illnesses in their lives. Depending on the definition and methods used to collect data, prevalence figures range from $10 \%$ to $20 \%$ (e.g. Nabors et al. 2008; Stein \& Johnson Silver 1999). Because of their illnesses, these children are more often, and for a longer period of time, absent from school than their healthy peers. This absenteeism is problematic for two reasons. On the one hand, education plays a major role in promoting cognitive development. In the literature it is stressed that children with a chronic or long-term illness are at increased risk of suffering from academic difficulties (Madan-Swain et al. 2004; Nabors \& Lehmkuhl 2004). This risk is particularly apparent in children who experience cognitive impairment as a direct consequence of the illness, or as a consequence of treatment. For other children mediating processes such as emotional difficulties and treatment-related effects (such as problems with attention and fatigue), might cause weaker school performances (Madan-Swain et al. 2004). Evidence of this risk is found in empirical research (e.g. Martinez \& Ercikan 2009). On the other hand, regular school attendance plays an important role in promoting a sense of normalcy for these children, and in developing psychosocial well-being. Positive experiences at school can help children achieve a sense of mastery and control, increase self-esteem, promote fulfilling peer relationships, and decrease emotional trauma resulting from the illness (Worchel-Prevatt et al. 1998). A chronic or long-term illness is an important life-event which can influence the psychosocial well-being of a child (Barlow \& Ellard 2006; Shaw \& McCabe 2008). Important areas of concern are peer relationships, body image and emotional reactions such as depression or anxiety (Worchel-Prevatt et al. 1998).

Nevertheless, children with a chronic or long-term illness often face barriers to successful school reintegration after a prolonged absence. These include school phobia or separation anxiety (Madan-Swain et al. 2004), social rejection due to misconceptions among peers regarding the illness and its contagiousness, and anxiety over physical changes, threatening the child's body image and self-esteem (Sexson \& Madan-Swain 1993). In the literature, much attention has been paid to school reintegration programmes which try to This is the peer reviewed version of the following article: Boonen, H., Petry, K. (2012). How do children with a chronic or long-term illness perceive their school re-entry after a period of homebound instruction?. Child: Care, Health and Development, 38 (4), 490-496, which has been published in final form at http://onlinelibrary.wiley.com/doi/10.1111/i.1365-2214.2011.01279.x/full. This article may be used for noncommercial purposes in accordance with Wiley Terms and Conditions for self-archiving. 
remove these barriers. These descriptive articles suggest various components of school reintegration programmes. Within these programmes, successful school re-entry is focused on meeting the unique needs of the individual child, ensuring continuing academic and social skill development by modifying the school environment, and assisting parents to be effective advocates for their children (Madan-Swain et al. 2004). Major goals of these programmes are sustaining or improving attendance and academic achievement for the child, educating classmates about the child's condition to facilitate understanding and foster peer relationships, teacher education and support and family support (Nabors \& Lehmkuhl 2004). Additional areas for intervention consist of the mental health needs of the child and the family, and improving social interactions and peer relationships (Sexson \& Madan-Swain 1995). Nevertheless, limited empirical data are available on the effectiveness of these school reintegration programmes (Madan-Swain et al. 2004; Prevatt et al. 2000).

Another way of reducing the barriers to school re-entry is homebound instruction, in which the educational process for the child is continued during the period of absence. In Flanders, since 1997, legislation provides for homebound instruction for children who are chronically or long-term ill. The homebound instruction is organized by the school in which the child is enrolled, and can be provided at home or at the hospital. The legislation makes a distinction between children who are chronically ill and children who are long-term ill. The latter group has a right to four hours homebound instruction a week after a period of 21 calendar days uninterrupted absence from school. The former group is entitled to four hours homebound instruction every time they build up nine half days absence from school. The major goal of homebound instruction is to maintain the child's academic level, principally by providing lessons in the main subjects (like mathematics and languages) and by testing the knowledge and skills of the child. The home teacher can be very flexible in organizing the lessons at home, taking into account the needs and health condition of the child. For example, teachers can also invest their time for the social-emotional support of the child, or for keeping the parents informed about the progress of their child. The home teacher is mostly a teacher from the school in which the child is enrolled and, in some cases, he or she is the child's class teacher. Consequently, the home teacher can provide a link between the child at home and his 
classmates at school, for example by organizing visits from classmates or by exchanging letters, postcards and drawings.

Despite the growing awareness of the necessity of education for children who are chronic or long-term ill, and the barriers that they face regarding school re-entry, there is still little empirical research available addressing programmes that facilitate school re-entry. Moreover, there is a lack of research in which homebound instruction is evaluated. With this research, we attempt to address this lack in the current knowledge base. More specifically, we will answer the following research questions: 1) How do parents and children experience the period of homebound instruction? 2) How do parents and children perceive school re-entry, both academically and social-emotionally? 3) What measures are taken by the child's school to facilitate school re-entry? 4) What is the contribution of homebound instruction to school re-entry from the point of view of the parents? To answer these questions, we will use a descriptive-explorative and multi-informant research design. These will enable us to explore widely the perspectives of both parents and children. Since, to our knowledge, no research has been done which has focused on school re-entry after a period of homebound instruction, we want to investigate the perspectives of the persons most concerned. In addition, children and parents each can offer their own experiences and views regarding the period of homebound instruction and school re-entry. For this reason, we will take both perspectives into account.

\section{METHODS}

\subsection{Participants}

The participants were children with a chronic or long-term illness who received homebound instruction and returned to school, and their parents. Participants were identified and recruited from a database of the Flemish Department of Education and Training in which schools which organized homebound instruction in the academic year 2008-2009 were listed. The database included 186 primary schools and 234 secondary schools. All schools were contacted. In total, 114 schools were willing to participate in the study. From these schools, 60 children with a chronic or long-term illness and their parents were selected based on the

This is the peer reviewed version of the following article: Boonen, H., Petry, K. (2012). How do children with a chronic or long-term illness perceive their school re-entry after a period of homebound instruction?. Child: Care, Health and Development, 38 (4), 490-496, which has been published in final form at http://onlinelibrary.wiley.com/doi/10.1111/i.1365-2214.2011.01279.x/full. This article may be used for noncommercial purposes in accordance with Wiley Terms and Conditions for self-archiving. 
inclusion criteria listed above. Sixty-five percent of the children were female; the mean age of the children was 14 years. The minimum age was seven years, with a maximum age of 19 years. Of the children, 36.2\% $(n=22)$ were at primary school and $63.8 \%(n=38)$ were at secondary school. With regard to the type of illness of the children, 6.7\% $(n=4)$ of the children had a psychological disorder, 15\% $(n=9)$ had some type of inflammation, $15 \%(n=$ 9) had a fracture or bone related disorder, $18.3 \%(n=11)$ had a disease related to immunity, $23.3 \%(n=14)$ had some type of cancer and, finally, for $21.7 \%$ of the children $(n=13)$ the disorder was not specified. Regarding the medical certificate for homebound instruction, $53.3 \%(n=32)$ of the children was categorized as having a long-term illness and $23.3 \%(n=$ 14) of the children as having a chronic illness. Data about the certificate are missing for $23.3 \%(n=14)$ of the children. For every child, one parent also filled in a questionnaire $(n=$ $60)$. No further information with regard to the parents was gathered.

Given the characteristics of our research sample, we took specific measures to respect the privacy and anonymity of the participants. Children could only participate in the study with the consent of their parents. In addition, anonymity and confidentiality was fully guaranteed in terms of the questionnaires for both parents and children. Since we approached our participants via the schools which organized the homebound instruction, we didn't have any access to personal information or identification data for the participants. In this way, the research procedure complied with the ethical standards as proposed by our university.

\subsection{Procedure and measures}

Since the literature on homebound instruction for children with a chronic or long-term illness is very scarce, a descriptive-explorative research design was chosen. In order to reach a large number of respondents, and to obtain a broad view, written questionnaires were used in which different aspects of the school re-entry process were considered. Three different questionnaires were constructed, namely one for parents, one for primary school-aged children and one for secondary school-aged children. In this way, differences in cognitive development and linguistic skills were taken into account. In order to make comparisons between the three groups of respondents, the content of the questionnaires was kept as parallel as possible. We opted for semi-structured questionnaires, which contain mainly closed This is the peer reviewed version of the following article: Boonen, H., Petry, K. (2012). How do children with a chronic or long-term illness perceive their school re-entry after a period of homebound instruction?. Child: Care, Health and Development, 38 (4), 490-496, which has been published in final form at http://onlinelibrary.wiley.com/doi/10.1111/j.1365-2214.2011.01279.x/full. This article may be used for noncommercial purposes in accordance with Wiley Terms and Conditions for self-archiving. 
questions, in various forms. For example, five-point scales, three-point scales and multiplechoice questions were used. This enabled us to collect data in a standardized way by giving all respondents the same questions in the same order. In addition, a few open questions were added, in which respondents were given the opportunity to share their perspectives and experiences on specific topics. The first part of the questionnaire was aimed at obtaining identification data with regard to the child such as gender, age and type of illness. The second part dealt with the period of homebound instruction. Parents and children were asked how they perceived this period, and what measures had been taken to facilitate school reintegration. Moreover, children were asked how they perceived social contact with peers during this period. The last part dealt with the re-entry into school. Parents and children were asked how they perceived both the academic and the social-emotional component of school re-entry, and what additional support they received when they returned to school. Furthermore, parents were asked about the contribution of the homebound instruction to the school re-entry of their child.

In the process of constructing the questionnaire, we intensively collaborated with experts from the field who had experience with education for ill children, both in practice and in policy. This made a positive contribution to the content validity of the questionnaires.

Questionnaires were sent by post to the school principal of all the schools within the database. In this way, all schools which organized homebound instruction in the academic year 2008-2009 throughout Flanders could be reached. In an introductory letter, the purpose of the study was explained, and the school principal was asked to pass the questionnaires to the teacher(s) who had organized homebound instruction. For these teachers, a letter was also added in which the purpose of the study was explained and in which the teachers were asked to pass the questionnaires to those pupils and their parents who had already re-entered school. Data collection was conducted during the period December 2009 - April 2010.

\subsection{Analyses}

Given the descriptive-explorative research design, analyses were performed at the item level. We extensively described the gathered data by calculating frequencies and measures of 
central tendency and dispersion. Furthermore, we examined answers to open questions by organizing them into broader categories. With respect to missing data, some questions were not answered by all respondents (item non-response). The percentage of non-response per question varied from $3 \%$ to $23 \%$, which can be considered as acceptable. One question with a missing data level of $37 \%$ was excluded from the analyses. To handle missing data, the method of pairwise deletion was chosen, by deleting only the unanswered items and not the whole observation (McKnight et al. 2007). This is appropriate since we only analysed the questions on an item level. Consequently, the presented percentages in the following section are based on the number of participants who answered the questions.

\section{RESULTS}

The first research question was directed toward the period of homebound instruction Parents and children both experienced the period of homebound instruction positively. On a scale from zero (very negative) to ten (very positive), the mean score of the parents was 8.84 $(S D=1.39)$. Children indicated their perception of their experience on a five-point scale, ranging from totally not pleased with homebound instruction to totally pleased with homebound instruction $\left(M d n=4 ; 1^{s t}\right.$ quartile $=3 ; 3^{\text {rd }}$ quartile $\left.=4\right)$. Children could also specify the reasons for their appreciation or otherwise of homebound instruction. The most important reason was that they enjoyed learning $(40 \% ; n=24)$, followed by the contact with the teacher $(30 \% ; n=18)$. Children also indicated that the lessons were interesting $(26.7 \% ; n$ $=16)$ and that they enjoyed having company $(26.7 \% ; n=16)$. Reasons why children didn't like homebound instruction were that the child often didn't feel like learning $(26.7 \% ; n=16)$, the child often felt too ill to learn $(25 \% ; n=15)$ and that the child didn't like that other people were aware of his or her illness $(23.3 \% ; n=14)$. Beside homebound instruction, $26.7 \%(n=$ 16) of the children got educational support from other sources, namely from Bednet (virtual contact between the child at home or at the hospital and his classmates and class teacher at school) $(15 \% ; n=9)$, hospital schools $(10 \% ; n=6)$, volunteer organizations $(5 \% ; n=3)$ and tutoring by a professional on a private basis $(3.3 \% ; n=2)$. A large proportion of the children $(91.7 \% ; n=55)$ stated that they kept in touch with their classmates during the period of This is the peer reviewed version of the following article: Boonen, H., Petry, K. (2012). How do children with a chronic or long-term illness perceive their school re-entry after a period of homebound instruction?. Child: Care, Health and Development, 38 (4), 490-496, which has been published in final form at http://onlinelibrary.wiley.com/doi/10.1111/i.1365-2214.2011.01279.x/full. This article may be used for noncommercial purposes in accordance with Wiley Terms and Conditions for self-archiving. 
homebound instruction. Children made contact with their classmates in several ways, namely via the internet $(58.2 \% ; n=32)$, by telephone $(56.4 \% ; n=31)$, through visits from classmates $(54.5 \% ; n=30)$. In addition, some children attended school at times $(22.2 \% ; n=12)$ and some children were connected with their classmates via a webcam $(10.9 \% ; n=7)$. Children were asked a few questions about the contact with classmates during their period of homebound instruction. Most of the children $(76.1 \% ; n=35)$ stated that the home school teacher tried to involve him or her in the class, even though he or she was absent, and $69.4 \%$ $(n=34)$ indicated that they felt part of their class. Besides, $90 \%$ of the children $(n=45)$ said that they missed their classmates during their absence. Almost every child indicated that his or her classmates were informed about the illness $(96.7 \% ; n=58)$.

The second research question examined how parents and children perceive their school re-entry. With respect to the academic component of returning to school, both parents and children were asked if the child has been able to keep up with his or her subjects at school. Almost half of parents $(44.6 \% ; n=25)$ indicated that his or her child was easily able to keep up. According to $42.9 \%$ of the parents $(n=24)$, this varied across subjects. Only a small proportion of parents $(12.5 \%, n=7)$ stated that their child experienced difficulties with regard to keeping up with his or her subjects. As regards the children, 50\% $(n=28)$ reported that they understood the majority of the lessons, 23.2\% $(n=13)$ that it varied across different subjects, $19.6 \%(n=11)$ that they understood all their lessons, and 7.1\% $(n=4)$ that most of the times they couldn't keep up with their subjects. Moreover, children were asked with which subjects they experienced difficulties. The most reported subject was mathematics (indicated by $42.6 \%$ of children, $n=23)$, followed by French $(31.5 \% ; n=17)$ ) and physics $(14.8 \%, n=8)$. Secondly, we investigated how parents and children perceived the social component of their school reintegration. Parents were asked if they thought that their child had good contact with his or her classmates; $84.5 \%$ of parents $(n=49)$ confirmed this statement. Using a five-point scale, the children could rate how they felt about social contact with their classmates in terms of not at all feeling at ease; usually not feeling at ease; sometimes feeling at ease, sometimes not feeling at ease; usually feeling at ease and feeling very much at ease. Nearly half of the children $(41.4 \%, n=24)$ stated that they usually felt at ease with their peers and $37.9 \%(n=22)$ that they felt very much at ease in terms of their This is the peer reviewed version of the following article: Boonen, H., Petry, K. (2012). How do children with a chronic or long-term illness perceive their school re-entry after a period of homebound instruction?. Child: Care, Health and Development, 38 (4), 490-496, which has been published in final form at http://onlinelibrary.wiley.com/doi/10.1111/j.1365-2214.2011.01279.x/full. This article may be used for noncommercial purposes in accordance with Wiley Terms and Conditions for self-archiving. 
social contact with peers. A small proportion of the children $(15.5 \% ; n=9)$ indicated that they sometimes felt at ease and sometimes did not feel at ease. Median and dispersion measures reflect these findings $\left(M d n=4 ; 1^{\text {st }}\right.$ quartile $=4 ; 3^{\text {rd }}$ quartile $\left.=5\right)$.

The third research question investigated which measures were taken by schools to foster the reintegration process of children who received a period of homebound instruction. More than half of the children $(68.4 \%, n=39)$ received some form of support when they were back at school. More children at secondary school level $(79 \%, n=30)$ had access to these resources in comparison with children at primary school level $(49 \%, n=9)$. When asked to specify the support they receive, children mentioned extra explanations during the lessons with the class teacher $(89.7 \% ; n=35)$, from classmates $(48.7 \% ; n=19)$ and from another teacher $(17.9 \% ; n=7)$; assistance with assignments and homework from the class teacher $(25.6 \% ; n=10)$, from classmates $(41 \% ; n=16)$ and from another teacher $(7.7 \% ; n=3)$; assistance while preparing tests and exams from the class teacher $(27.6 \% ; n=8)$, from classmates $(13.8 \% ; n=4)$ and from another teacher $(10.3 \% ; n=3)$. With respect to the point in time of the support, children received most support during lessons $(61.5 \% ; n=24)$ and during school breaks $(56.4 \% ; n=22)$. A small proportion of the children also received support after school $(23.1 \% ; n=9)$, during the weekends $(10.3 \% ; n=4)$ and during holidays $(12.8 \% ; n=5)$.

The fourth research question examined the opinion of parents about the contribution of homebound instruction to the school reintegration of their children. Parents were given five propositions which they could respond to on a five-point scale, with 1 standing for not agree, 2 for rather not agree, 3 for nor agree, nor disagree, 4 for rather agree and 5 for agree. Overall, parents valued highly the contribution of homebound instruction. They agreed that homebound instruction stimulated the development of their child $\left(M d n=5 ; 1^{s t}\right.$ quartile $=4$; $3^{\text {rd }}$ quartile = 5), gave their child the feeling to having a future $\left(M d n=4 ; 1^{\text {st }}\right.$ quartile $=4 ; 3^{\text {rd }}$ quartile $=5)$ and involved the child in the life of the school $\left(\left(M d n=5 ; 1^{\text {st }}\right.\right.$ quartile $=4 ; 3^{\text {rd }}$ quartile $=5$ ). With respect to the proposition that homebound instruction encouraged the connection between their child and his or her class and classmates, the opinions of parents are more divided $\left(M d n=4: 1^{\text {st }}\right.$ quartile $=2.25 ; 3^{\text {rd }}$ quartile $\left.=5\right)$. More than half of parents answered positively with regard to this proposition $(61.7 \%$ gave a score from 4 or $5 ; n=37)$, This is the peer reviewed version of the following article: Boonen, H., Petry, K. (2012). How do children with a chronic or long-term illness perceive their school re-entry after a period of homebound instruction?. Child: Care, Health and Development, 38 (4), 490-496, which has been published in final form at http://onlinelibrary.wiley.com/doi/10.1111/j.1365-2214.2011.01279.x/full. This article may be used for noncommercial purposes in accordance with Wiley Terms and Conditions for self-archiving. 
but also 25\% $(n=15)$ of parents did (rather) not agree. The group of parents that indicated that homebound instruction had contributed to the social contact of their child with classmates was asked in which way the homebound instruction had made a contribution. Eleven parents answered that the teacher actively stimulated the contact between their child and classmates in several ways, such as by keeping the child informed about the class, by coming to visit with classmates, by allowing chatting and phone calls from the classmates during school time, and by bringing letters and cards from classmates. Two parents answered that the teacher contributed by informing the classmates about the illness of their child. In this way, classmates were able to have a better understanding of the situation. One parent answered that homebound instruction prevented the child from building up arrears, and in this way made the child feel that s/he was not on his or her own. Besides, parents who answered that the homebound instruction didn't contribute to the social contacts of their child were asked if they thought that homebound instruction should have contributed and how this might be possible. Six parents shared the view that it is not the task of homebound instruction to stimulate social contact with peers, and some parents stated that the main focus should be on the academic component. According to four parents, homebound instruction doesn't have the means for stimulating the social reintegration process. Only two parents indicated that homebound instruction could had made a greater contribution by telling classmates about the illness and the situation of the child, and by keeping the child informed about the class.

\section{DISCUSSION}

A considerable number of children are confronted with a chronic or long-term illness in their lives. These children are more often, and for a longer period of time, absent from school than their healthy peers. This absenteeism is problematic, because education plays a major role in stimulating the cognitive development of the child and in promoting a sense of normalcy and psychosocial well-being. In the literature, a great deal of attention has been paid to school reintegration programmes which try to overcome the barriers that these children might face when they return to school. Another way of surmounting these barriers is through the use of homebound instruction, in which the academic educational process for the child is This is the peer reviewed version of the following article: Boonen, H., Petry, K. (2012). How do children with a chronic or long-term illness perceive their school re-entry after a period of homebound instruction?. Child:

Care, Health and Development, 38 (4), 490-496, which has been published in final form at http://onlinelibrary.wiley.com/doi/10.1111/i.1365-2214.2011.01279.x/full. This article may be used for noncommercial purposes in accordance with Wiley Terms and Conditions for self-archiving. 
continued during the period of absence. In our study, we investigated how parents and their children with a chronic or long-term illness perceive school re-entry after a period of homebound instruction.

Firstly, we were interested in how parents and children experienced the period of homebound instruction. Both children and parents evaluated this period positively. During this period, almost all of the children kept in touch with their classmates in various ways. Furthermore, the majority of children indicated that they felt part of their class and that the school teacher tried to involve him or her. This finding is in contrast with the findings of the study by Bessel (2001), one of the very few studies on homebound instruction. This study revealed that homebound instruction was perceived to be academically inadequate and socially isolating for post-treatment survivors of paediatric cancer. In our study, however, the image of homebound instruction is more positive. An important remark is that one quarter of the children received additional support, for example through extra hours of homebound instruction given by volunteers or paid tutors. This finding should be taken into account when interpreting the other results. Possibly, for some of the children, four hours homebound instruction a week is too limited. Moreover, the impact of the current widespread use of social networking via the internet and communicating with others via e-mail must be considered when comparing the results of our study with Bessel's study. The growing opportunities for children to keep in touch with their peers via the internet can possibly contribute to the fact that homebound instruction is no longer perceived as being socially isolating (Battles \& Wiener 2002; Straker et al. 2009).

Secondly, we investigated how parents and children perceive both the academic and social-emotional component of school re-entry. We can conclude that parents and children are predominantly positive about school re-entry. Despite the numerous barriers to smooth school re-entry reported in the literature, most of the participants in this study indicated that they were able to keep up with their subjects and that they usually had good contact with their peers at school. An important point to make is that we only focused on the perspectives of parents and children, and that no objective measures of academic achievement and social integration were included. We believe, however, that these views are in themselves very 
valuable. Future research could include these objective measures. Furthermore, it would be interesting to investigate what factors contribute to successful school reintegration. For instance, an important variable that we didn't include in our study is the length of absence due to illness. Connected with this, the severity and type of illness play a seminal role in children's adjustment and social acceptance (Nabors \& Lehmkuhl 2004). Besides, the presence of close peer contact when the child is absent from school is an important factor. Close contact with peers can prevent social discomfort and anxiety related to school re-entry (Bessel 2001; Sexson \& Madan-Swain 1995). School phobia or separation anxiety is another factor that can complicate the school reintegration process (Madan-Swain et al. 2004). Further research is needed to examine the influence of these factors.

Thirdly, we examined what measures were taken by the child's school to facilitate school re-entry. More than half of the children received some form of support when returning to school. Examples of this support are extra explanations during the lessons or assistance with assignments and homework, given by the class teacher or classmates. In addition, more children at secondary school level than children at primary school level received such support. This is not surprising, given the fact that homebound instruction is limited to four hours a week. Consequently, during homebound instruction, only the main subjects can be included. For future research, it would be interesting to further examine the differences in educational needs between primary and secondary school age children.

Fourthly, we were interested in the view of parents about the contribution of homebound instruction to the school re-entry of their child. Parents obviously agreed that homebound instruction stimulated the development of their child, gave their child the feeling of having a future, and involved their child in the life of the school. Nevertheless, the opinions of the parents were divided on the contribution of homebound instruction to the social contact with peers. Interestingly, almost all of the children stated that they kept in touch with their classmates during their absence. However, only a group of parents indicated that the homebound instruction teacher actively or more indirectly stimulated the contact with peers. According to another group of parents, homebound instruction should or can only focus on the academic component. In the literature, the importance of close peer contact during the 
period of absence is stressed (Bessel 2001; Sexson \& Madan-Swain 1995). Further research is needed to explore the social reintegration process of children with a chronic or long-term illness who receive homebound instruction, and to investigate what factors are related to the maintenance of peer contact.

There are several limitations to the current study that should be mentioned. With regard to the research sample, due to the rather limited sample size, there is a lack of statistical power. Consequently, significant differences between groups are hard to find. For example, based on the literature, it would have been interesting to investigate if children with various types of diseases have different experiences concerning their school re-entry. In our study, however, subsamples of children with different types of illnesses were very small. Furthermore, our research sample is based upon a database provided by the Flemish Department of Education and Training of schools who organized homebound instruction in the year 2008-2009. Hence, the generalizability of the current research needs to be treated with caution. Moreover, we are aware that a questionnaire is limited when it comes to exploring the perspectives and experiences of parents and their children with chronic or longterm illness. Further research is needed in which more qualitative, in-depth data are gathered, for example by interviews or case studies. An example of this approach is the study by Bruce et al. (2008), in which the school experiences of the families of children with brain tumours were explored by using interviews, and by organizing these data into broader categories, namely academic challenges, social difficulties and helpful resources.

To conclude, the current study is one of the first to explore the school re-entry of children with a chronic or long-term illness after a period of homebound instruction. Therefore we have chosen a descriptive-explorative and multi-informant research design, which enabled us to explore this new research topic widely. Nevertheless, we are aware that we made a certain selection, and that other research questions could also have been addressed. Hence, the strength of our research is that various directions for future research are formulated. We strongly believe that there is a need for more research directed towards the educational situation of children who are chronic or long-term ill. More specifically, research 
should examine the quality of education and the programmes aimed at facilitating school reentry. In this way, we can contribute to the right of every ill child to high-quality education.

\section{KEY MESSAGES}

$>$ Perspectives of parents and children on homebound instruction were examined.

$>$ Homebound instruction contributes to a smooth school reentry. $>$ Homebound instruction is valuable for cognitive development. >During absence, children keep in touch with their classmates.

\section{REFERENCES}

Barlow, J. H. \& Ellard, D. R. (2006). The psychosocial well-being of children with chronic disease, their parents and siblings: an overview of the research evidence base. Child: Care, Health and Development, 32, 19-31.

Battles, H. B. \& Wiener, L. S. (2002). STARBRIGHT World: effects of an electronic network on the social environment of children with life-threatening illnesses. Children's Health Care, 31, 47-68.

Bessel (2001). Children surviving cancer: Psychosocial adjustment, quality of life and school experiences. Exceptional Children, 67, 345-359.

Bruce, B. S., Chapman, A., MacDonald, A. \& Newcombe, J. (2008). School experiences of families of children with brain tumors. Journal of Pediatric Oncology Nursing, 25, 331-339.

Madan-Swain, A., Katz, E. R. \& LaGory, J. (2004). School and social reintegration after a serious illness or injury. In: Handbook of pediatric psychology in school settings (ed. R. T. Brown), pp. 637-654. Lawrence Erlbaum Associates, Mahwah/New Jersey, US.

This is the peer reviewed version of the following article: Boonen, H., Petry, K. (2012). How do children with a chronic or long-term illness perceive their school re-entry after a period of homebound instruction?. Child: Care, Health and Development, 38 (4), 490-496, which has been published in final form at http://onlinelibrary.wiley.com/doi/10.1111/i.1365-2214.2011.01279.x/full. This article may be used for noncommercial purposes in accordance with Wiley Terms and Conditions for self-archiving. 
Martinez, Y. J. \& Ercikan, K. (2009). Chronic illnesses in Canadian children: what is the effect of illness on academic achievement, and anxiety and emotion disorders? Child: Care, Health and Development, 35, 391-401.

Mcknight, P. E., Mcknight, K. M., Sidani, S. \& Figueredo, A. J. (2007). Missing data: a gentle introduction. The Guilford Press, New York, US.

Nabors, L. A. \& Lehmkuhl, H. D. (2004). Children with chronic medical conditions: recommendations for school mental health clinicians. Journal of Developmental and Physical Disabilities, 16, 1-15.

Nabors, L. A., Little, S. G., Akin-Little, A. \& Iobst, E. A. (2008). Teacher knowledge of and confidence in meeting the needs of children with chronic medical conditions: pediatric psychology's contribution to education. Psychology in the Schools, 45, 217226.

Prevatt, F. F., Heffer, R. W. \& Lowe, P. A. (2000). A Review of School Reintegration Programs for Children with Cancer. Journal of School Psychology, 38, 447-467.

Sexson, S. B. \& Madan-Swain, A. (1993). School reentry for the child with chronic illness. Journal of Learning Disabilities, 28, 115-125, 137.

Sexson, S. \& Madan-Swain, A. (1995). The Chronically Ill Child in the School. School Psychology Quarterly, 10, 359-368.

Shaw, S. R. \& McCabe, P. C. (2008). Hospital-to-school transition for children with chronic illness: meeting the new challenges of an evolving health care system. Psychology in the Schools, 45, 74-87.

Stein, R. E. K. \& Johnson Silver, E. (1999). Operationalizing a conceptually based noncategorical definition: A first look at U.S. children with chronic conditions. Archives of Pediatrics \& Adolescent Medicine, 153, 68-74.

Straker, L., Pollock, C. \& Maslen, B. (2009). Principles for the wise use of computers by children. Ergonomics, 52, 1386-1401.

This is the peer reviewed version of the following article: Boonen, H., Petry, K. (2012). How do children with a chronic or long-term illness perceive their school re-entry after a period of homebound instruction?. Child: Care, Health and Development, 38 (4), 490-496, which has been published in final form at http://onlinelibrary.wiley.com/doi/10.1111/i.1365-2214.2011.01279.x/full. This article may be used for noncommercial purposes in accordance with Wiley Terms and Conditions for self-archiving. 
Worchel-Prevatt, F. F., Heffer, R. W., Prevatt, B. C., Miner, J., Young-Saleme, T., Horgan, D. \& Lopez, M. A. (1998). A School Reentry Program for Chronically Ill Children. Journal of School Psychology, 36, 261-279.

This is the peer reviewed version of the following article: Boonen, H., Petry, K. (2012). How do children with a chronic or long-term illness perceive their school re-entry after a period of homebound instruction?. Child: Care, Health and Development, 38 (4), 490-496, which has been published in final form at http://onlinelibrary.wiley.com/doi/10.1111/i.1365-2214.2011.01279.x/full. This article may be used for noncommercial purposes in accordance with Wiley Terms and Conditions for self-archiving. 